\title{
European guidelines for quality assurance in colorectal cancer screening and diagnosis: Overview and introduction to the full Supplement publication
}

Authors

Institutions
European Colorectal Cancer Screening Guidelines Working Group:

L. von Karsa', J. Patnick',3, N. Segnan ${ }^{1,4}$, W. Atkin ${ }^{5}$, S. Halloran ${ }^{6,7}$, I. Lansdorp-Vogelaar ${ }^{8}$, N. Malila ${ }^{9}$, S. Minozzi ${ }^{4}$, S. Moss ${ }^{10}$, P. Quirke ${ }^{11}$, R. J. Steele ${ }^{12}$, M. Vieth ${ }^{13}$, L. Aabakken ${ }^{14}$, L. Altenhofen ${ }^{15}$, R. Ancelle-Park ${ }^{16}$, N. Antoljak ${ }^{17,18}$, A. Anttila ${ }^{9}$, P. Armaroli ${ }^{4}$, S. Arrossi ${ }^{19}$, J. Austoker ${ }^{20, \dagger}$, R. Banzi ${ }^{21}$, C. Bellisario ${ }^{4}$, J. Blom ${ }^{22}$, H. Brenner ${ }^{23}$, M. Bretthauer ${ }^{24}$, M. Camargo Cancela ${ }^{25,26}$, G. Costamagna ${ }^{27}$, J. Cuzick ${ }^{28}$, M. Dai ${ }^{29}$, J. Daniel ${ }^{26,30}$, E. Dekker ${ }^{31}$, N. Delicata ${ }^{32}$, S. Ducarroz ${ }^{1}$, H. Erfkamp ${ }^{33}$, J. A. Espinàs ${ }^{34}$, J. Faivre ${ }^{35}$, L. Faulds Wood ${ }^{36}$, A. Flugelman ${ }^{37}$, S. Frkovic-Grazio ${ }^{38}$, B. Geller ${ }^{39}$, L. Giordano ${ }^{4}$, G. Grazzini ${ }^{40}$, J. Green ${ }^{20}$, C. Hamashima ${ }^{41}$, C. Herrmann ${ }^{26,42}$, P. Hewitson ${ }^{20}$, G. Hoff ${ }^{43,44}$, I. Holten ${ }^{45}$, R. Jover ${ }^{46}$, M. F. Kaminski ${ }^{47}$, E. J. Kuipers ${ }^{8}$, J. Kurtinaitis ${ }^{48}$,, R. Lambert ${ }^{1}$, G. Launoy ${ }^{49}$, W. Lee ${ }^{50}$, R. Leicester ${ }^{51}$, M. Leja ${ }^{52}$, D. Lieberman $^{53}$, T. Lignini ${ }^{1}$, E. Lucas ${ }^{1}$, E. Lynge ${ }^{54}$, S. Mádai ${ }^{55}$, J. Marinho ${ }^{56}$, J. Maučec Zakotnik ${ }^{57}$, G. Minoli ${ }^{58}$, C. Monk ${ }^{59}$, A. Mor$a_{i s}^{60}$, R. Muwonge ${ }^{1}$, M. Nadel ${ }^{61}$, L. Neamtiu ${ }^{62}$, M. Peris Tuser ${ }^{63}$, M. Pignone ${ }^{64}$, C. Pox ${ }^{65}$, M. Primic-Zakelj ${ }^{66}$, J. Psaila ${ }^{32}$, L. Rabeneck ${ }^{67}$, D. Ransohoff ${ }^{64}$, M. Rasmussen ${ }^{68}$, J. Regula ${ }^{47}$, J. Ren ${ }^{26}$, G. Rennert ${ }^{37}$, J. Rey ${ }^{69}$, R. H. Riddell ${ }^{70}$, M. Risio ${ }^{71}$, V. Rodrigues ${ }^{72}$, H. Saito ${ }^{41}$, C. Sauvaget ${ }^{1}$, A. Scharpantgen ${ }^{73}$, W. Schmiegel ${ }^{65}$, C. Senore ${ }^{4}$, M. Siddiqi ${ }^{74}$, D. Sighoko ${ }^{26,75}$, R. Smith ${ }^{30}$, S. Smith ${ }^{76}$, S. Suchanek ${ }^{77}$, E. Suonio ${ }^{1}$, W. Tong ${ }^{78}$, S. Törnberg ${ }^{79}$, E. Van Cutsem ${ }^{80}$, L. Vignatelli ${ }^{81}$, P. Villain ${ }^{20}$, L. Voti ${ }^{26,82}$, H. Watanabe ${ }^{83}$, J. Watson ${ }^{20}$, S. Winawer ${ }^{84}$, G. Young ${ }^{85}$, V. Zaksas ${ }^{86}$, M. Zappa ${ }^{40}$, R. Valori ${ }^{87}$

Institutions are listed at the end of the article. submitted 10. October 2012 accepted after revision 26. October 2012

\section{Bibliography}

Dol http://dx.doi.org/ 10.1055/s-0032-1325997 Published online: 4.12.2012 Endoscopy 2013; 45: 51-59 (c) Georg Thieme Verlag KG Stuttgart · New York ISSN 0013-726X

Corresponding author: L. von Karsa, MD Quality Assurance Group, Early Detection and Prevention Section International Agency for Research on Cancer 150 cours Albert Thomas 69372 Lyon Cedex 08 France Fax: +33-47-2738351 karsal@iarc.fr

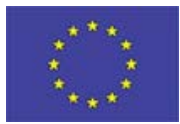

Co-Funded by the Health Programme of the European Union

Link to the guideline supplement:

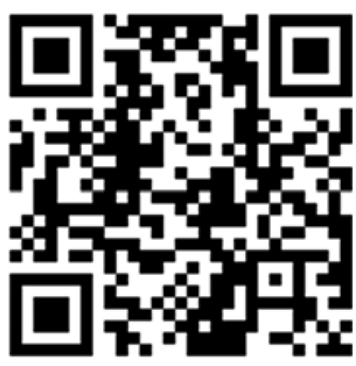

http://goo.gl/ZPEHt
Population-based screening for early detection and treatment of colorectal cancer (CRC) and precursor lesions, using evidence-based methods, can be effective in populations with a significant burden of the disease provided the services are of high quality. Multidisciplinary, evidence-based guidelines for quality assurance in CRC screening and diagnosis have been developed by experts in a project co-financed by the European Union. The 450-page guidelines were published in book format by the European Commission in 2010. They include 10 chapters and over 250 recommendations, individually graded according to the strength of the recommendation and the supporting evidence. Adoption of the recommendations

\section{Introduction}

\section{$\nabla$}

According to recent estimates by the International Agency for Research on Cancer [1], colorectal cancer (CRC) is the most common cancer in Europe with 432000 new cases reported annually in men and women combined. It is the second most common cause of cancer deaths in Europe with 212000 deaths reported in 2008. Worldwide, CRC ranks third in incidence and fourth in mortality with an estimated 1.2 million cases and 0.6 million deaths annually. In the 27 Member States of the European Union (EU), CRC ranks first in incidence and second in mortality, with approximately 334000 new cases and 149000 deaths estimated in 2008. Even in those Member States in the lower range for age-standardized rates of $\mathrm{CRC}$, the burden of disease is significantly greater when compared with many other regions of the world (see reference [1]). CRC is therefore an important health problem across the EU.

Screening can be effective in cancer control in populations with a significant burden of CRC,

\footnotetext{
$\dagger$ Deceased
}

can improve and maintain the quality and effectiveness of an entire screening process, including identification and invitation of the target population, diagnosis and management of the disease and appropriate surveillance in people with detected lesions. To make the principles, recommendations and standards in the guidelines known to a wider professional and scientific community and to facilitate their use in the scientific literature, the original content is presented in journal format in an open-access Supplement of Endoscopy. The editors have prepared the present overview to inform readers of the comprehensive scope and content of the guidelines.

provided the services are of high quality [2]. The aim of CRC screening is to lower the burden of cancer in the population by discovering disease in its early, latent stages [3]. Evidence-based methods permit treatment that is more effective than if disease is diagnosed later when symptoms have occurred. Early treatment of invasive lesions, for example by endoscopic resection of early CRC, can also be less detrimental for quality of life. The endoscopic removal of pre-malignant lesions also reduces the incidence of CRC by avoiding the progression to cancer. Randomized trials in people of average risk invited to participate in screening have shown a reduction in CRC incidence [4-7] and mortality $[4,7-10]$.

The EU recommends population-based screening for breast, cervical and colorectal cancer using evidence-based methods with quality assurance of the entire screening process [11]. The EU policy takes into account the principles of cancer screening developed by the World Health Organization [12] and the extensive experience in the EU in piloting and implementing population-based cancer screening programmes [13]. Comprehensive European quality assurance guidelines for breast and cervical cancer screening have been devel- 
oped by experts and published by the EU $[14,15]$. The new European guidelines for quality assurance in colorectal cancer screening and diagnosis $[3,16-27]$ make similar principles, standards and recommendations available to healthcare professionals, scientists, decision-makers and other stakeholders seeking to establish or improve CRC screening programmes.

The content of the evidence-based multidisciplinary guidelines is presented in 13 articles in a recent Supplement to Endoscopy. Each article covers one of the 10 chapters of the guidelines [ 3 , $16-24]$, the annex of the chapter dealing with quality assurance in pathology [25], the section on principles of evidence assessment and methods for reaching recommendations [28], or the executive summary [26]. The results section of each chapter article begins with a list of key recommendations with a dual grading showing the strength of each recommendation and the supporting evidence. The annotation of each recommendation also indicates the places in the text where the evidence pertaining to each recommendation is explained, including cross-references to other chapters. This enables the reader to rapidly review the key content of the guidelines and to identify places in the volume likely to be of interest for further reading. In total, 750 references are cited and more than 250 graded recommendations are explained. In addition, some statements of advisory character considered to be good practice but not sufficiently important to warrant formal grading are provided in each chapter.

The guidelines address the quality issues in screening of the average-risk population in which most CRC develops. Given the moderate geographic variation in the population risk of CRC across the EU [1], no attempt was made to develop recommendations tailored to people with moderate risk due to family history of CRC. However, people identified with a family history of CRC, but not presenting with a hereditary syndrome should be included in the average-risk screening; see Chapter 2 [16]. High-risk individuals should be referred for alternative and more intensive protocols if those are available. The potential benefit and harm of screening recommendations tailored to people with a family history should be examined in greater depth in the preparation of the next edition of the EU guidelines.

The methods used in developing the guidelines are described in greater detail elsewhere $[28,29]$. Briefly, a multidisciplinary group of authors and editors experienced in quality assurance in CRC screening, programme implementation and guideline development collaborated with a 'literature group' consisting of epidemiologists with special expertise in the field of CRC and in systematic literature review. The 'literature group' systematically retrieved, evaluated and synthesized relevant publications according to clinical questions defined by the authors and editors. Bibliographic searches were performed using MeSH terms and freetext words. For most clinical questions searches were limited to the years 2000 to 2008 and were performed on Medline, and in many cases also on Embase and the Cochrane library databases. Additional searches were conducted without date restrictions or starting before 2000 if the authors or editors who were experts in the field knew that there were relevant articles published before 2000. Articles of adequate quality recommended by authors because of their clinical relevance were also included. In selected cases references not identified by the 'literature group' were included in the evidence base, i.e., when authors found relevant articles published after 2008 during the period up to October 2010 when the chapter manuscripts were drafted and revised prior to publication. The methodological quality of the retrieved publications was assessed using the criteria obtained from published and validated checklists [30-35]. Preliminary versions of the draft guidelines were repeatedly reviewed and revised through multidisciplinary meetings attended by the authors, editors and the 'literature group', as well as in pan-European network meetings with participants from all of the 27 EU Member States. Prior to finalization of the guidelines, all of the chapters except the introduction were reviewed by external experts from Australia, Canada, France, Japan, Norway, Poland, Switzerland, the United Kingdom and the United States of America.

An extensive body of scientific evidence was systematically collected and reviewed in the preparation of the guidelines. Approximately two years have passed since work on the first edition was completed and knowledge in the field of CRC screening continues to expand. In our appraisal, more recent literature would justify revision of the grading of the evidence for some recommendations, and in some cases the strength of a recommendation could be increased. A continuous update of the scientific evidence on colorectal cancer screening is therefore needed in order to provide timely changes to the recommendations on quality assurance for colorectal cancer screening.

The authors and editors welcome comments, suggestions and reporting of any errors noticed by the reader. They are a valuable source of information for preparation of the next guidelines edition.

\section{Overview of the guidelines content \\ $\nabla$}

Throughout the text emphasis is placed on best practice at each step in the multidisciplinary screening process. The guidance includes both methods for avoiding and practical approaches to solving medical, organizational and technical problems in the selection and use of faecal occult blood tests, in endoscopy for diagnosis or screening, in pathology, and in the clinical management and surveillance of people with lesions detected in screening. Cross-cutting themes, such as communication, documentation, evaluation and training, that are crucial to ensuring high quality in the provision of screening services are also covered. The numerous guiding principles, evidence-based recommendations and conclusions presented in the guidelines cannot all be presented here. The following points are highlighted to illustrate the scope and depth of the first edition.

\section{Evidence for the effectiveness of CRC screening}

The first chapter presents the evidence that was available in late 2010 for the effectiveness and cost-effectiveness of CRC screening and for key operational parameters such as age range, interval between two negative screening examinations and some combinations of tests [3]. The 17 graded recommendations and conclusions reflect the large body of evidence on the primary screening method that is recommended by the EU (faecal occult blood testing, FOBT) [11]. Most of the FOBT randomized trials were performed with guaiac-based tests, but the EU guidelines confirm that faecal immunochemical testing (FIT) also fulfils the requirements of the EU for primary screening $[3,11]$. At the time of the original publication, reasonable evidence for the efficacy of flexible sigmoidoscopy screening was available from a large randomized trial, and there was limited evidence for the efficacy of colonoscopy screening. There is now good evidence from large randomized trials involving over 300000 men and women that screening with flexible sigmoidoscopy can substantially reduce colorectal cancer incidence $[4,6,7]$ and mortality $[4,7]$. 


\section{Organization of a colorectal screening programme}

The 29 recommendations and conclusions in the second chapter cover the key organizational aspects that influence the quality and effectiveness of a CRC screening programme [16]. They reflect the broad consensus in the $\mathrm{EU}$ on the fundamental principle that a CRC screening programme is a multidisciplinary process. The effectiveness of a programme is a function of the quality of each of the individual components of the process. Organized screening as opposed to spontaneous case-finding is essential to achieve and maintain appropriate quality.

The provision of a screening service must take into account the values and preferences of individuals concerned as well as public health considerations. The public health perspective in the planning and provision of screening services requires commitment to ensuring equity of access and sustainability of the programme over time. Adequate consideration for the perspective of the individual requires commitment to promoting informed participation and to providing a high-quality, safe service.

Successful implementation of a screening programme entails more than simply carrying out the screening tests and referring individuals to assessment where indicated. Specific protocols such as those used in call and recall systems must be developed for identifying and inviting the target population to attend screening or assessment of screen-detected abnormalities, and for monitoring cause of death. Protocols are also required for patient management in the diagnosis, treatment and surveillance phases to ensure that all individuals have timely access to appropriate diagnostic and treatment options. In addition, irrespective of the organizational approach, political and financial support is crucial to the successful implementation of any screening programme.

\section{Evaluation and interpretation of screening outcomes}

The third chapter contains 20 graded recommendations on the processes and procedures required for effective monitoring and evaluation of CRC screening programmes [17]. Of fundamental importance is the complete and accurate recording of all relevant data on each individual and every screening test performed. This includes both the information needed for the invitation system, which is best provided by an accurate population database, as well as individual test results, further diagnostic procedures and the final outcome of screening, and serious adverse effects. CRC incidence and mortality must be monitored and comprehensive systems must be developed to document the screening process, monitor data completeness and quality, and accurately compile and report results. Key measures, indicators and standards for monitoring programme performance and evaluating screening impact are recommended, some of which require linkage of screening data with data from other sources, such as cancer registries. The standards are based on an overview of performance measures available from published trial results and populationbased screening programmes.

Performance indicators are essential for the supervision of a programme and for the provision of regular information to decision makers. The authors stress the importance of incorporating evaluation of the programme into the protocols adopted for the screening process before screening begins. This should ensure that the evaluation components are implemented from the very start of the programme.

\section{Faecal occult blood testing}

The fourth chapter includes 21 detailed recommendations concerning the design, application and selection of appropriate FOBTs in CRC screening [18]. The ideal biochemical test for population screening of CRC would use a biomarker, specific and sensitive for cancer and advanced pre-cancer, with an easily collected sample that could be safely and cheaply transported to a centralized laboratory for accurate, reproducible and inexpensive automated analysis. Although none of the currently available tests are ideal, the faecal immunochemical test (FIT) for haemoglobin and the guaiac-based faecal occult blood test (gFOBT) for men and women aged 50-74 years fulfil the criteria for screening recommended by the Council of the EU.

Immunochemical tests have improved test characteristics compared with conventional guaiac-based tests. They are both analytically and clinically more sensitive and specific for the detection of haemoglobin. Their measurement can be automated and the user can determine the concentration at which a result is designated positive. By changing the designated 'cut-off' concentration, the proportion of false-positive tests and the number of colonoscopies performed can be adjusted to meet local requirements. Quantitative immunochemical tests are currently the test of choice for population screening; however, individual device characteristics, including ease of use by the participant and laboratory, suitability for transport, sampling reproducibility and sample stability are all important when selecting the FIT most appropriate for an individual screening programme.

Guaiac-based FOBTs have proven characteristics that make them suitable for population screening. However, they lack the specificity and sensitivity of immunochemical tests for the detection of haemoglobin, their analysis cannot be automated and the concentration at which they turn from negative to positive cannot be adjusted by the user. For these reasons guaiac-based tests are not the preferred test for new population screening programmes, although, depending on local labour costs, the mechanism of kit distribution and collection and the reduced sample stability in immunochemical tests, they might prove more practicable and affordable than immunochemical testing.

The authors and editors of the EU guidelines also stress the importance of centralized laboratory processing of screening tests and participation in laboratory external quality assurance schemes.

\section{Quality assurance of endoscopy in CRC screening and diagnosis}

A comprehensive view of the many-faceted aspects of quality assurance of endoscopy used for follow-up examinations as well as for primary screening is presented in Chapter 5 [19]. The complexity of the subject is reflected by the comparatively large number of specific recommendations (50 in total) that deal with planning and location of endoscopic services, infrastructure and equipment, preparation of the patient and aftercare, endoscopic technique, endoscopists' performance, quality improvement, policies and processes. Provision of the service must take into account the perspectives of endoscopists and public health to ensure that the experience is high-quality, safe and efficient as well as people-oriented. Furthermore, historic development within different local and cultural contexts should be taken into account. The organization of the chapter reflects the patient journey through screening and follow-up. This approach reflects the consensus of the authors and editors that screening and symptomatic (diagnostic) services should achieve the same minimum 
levels of quality and safety. Wherever possible, the quality assurance required for screening should have an enhancing effect on the quality of endoscopy performed for symptomatic patients. All people undergoing endoscopy, whether for primary screening, for assessment of abnormalities detected through screening, for assessment of symptoms or for surveillance, should have as good an experience as possible. They should be confident enough in the quality of the procedure developed to be able to recommend screening, assessment and surveillance of appropriate quality to their friends, family and colleagues.

\section{Professional requirements and training}

The 23 graded recommendations in Chapter 6 deal with professional and other requirements for screening staff [20]. Special training of the multidisciplinary team that is involved in the screening programme is required. The team includes administrative and clerical staff, epidemiologists, laboratory staff, primary care physicians, endoscopists, radiologists, pathologists, surgeons, nurses and public health specialists.

All staff involved in the delivery of a CRC screening programme should know the basic principles of CRC screening. The need for specialist training in screening differs between the various disciplines and is most important for those involved in the planning and delivery of the service and diagnosis, e.g. epidemiologists, laboratory staff, endoscopists, radiologists, pathologists and nurses.

\section{Quality assurance in pathology in CRC screening and diagnosis}

The pathology service plays a crucial role in CRC screening because the clinical and subsequent management of participants in the programme depends on the quality and accuracy of the diagnosis. Pathology affects the decision to undergo further local and/or major resection as well as surveillance after screening. Chapter 7 contains 23 graded recommendations for pathology, concentrating on areas of clinical importance within a screening programme [21]. The associated annex discusses some of the more difficult areas and suggests topics for future research. The authors recognize that this is the first edition of what will be a continuing process of revision as new data emerge on the pathology, screening and management of CRC. It is also hoped that by setting minimum standards, these will be followed in all programmes and hence encourage the development of higher standards amongst the pathology community and screening programmes. Guidelines for the reporting and management of resected specimens have been included in an attempt to also move towards agreed minimum European standards of pathology in these areas. This will improve the clinical relevance of information obtained through evaluation and monitoring and should also facilitate the exchange of information and experience between programmes by making data and results more comparable.

The authors and editors of the EU guidelines also stress the importance of participation in external quality assurance schemes for pathology services.

\section{Management of lesions detected in CRC screening}

The screening process can only be successful if timely and appropriate management follows early detection of lesions. Chapter 8 contains 32 graded recommendations on management of lesions detected in CRC screening [22]. In essence, the management of screen-detected adenomas and carcinomas does not differ, stage for stage, from that required for symptomatic disease. However, screening detects a different spectrum of disease compared with that diagnosed in the symptomatic population (i.e., there is a higher proportion of early disease). Some considerations in the management of screen-detected disease are therefore emphasized in this chapter of the guidelines.

Of prime importance is the wide consensus on the principle that colorectal neoplasia is best managed by a multidisciplinary team. The relevant disciplines include surgery, endoscopy, pathology, radiology, radiotherapy, medical oncology, specialist nursing, genetics and palliative care [36]; these should work in close collaboration with primary care. Furthermore, it is recognized that the interval between the diagnosis of screen-detected disease and the start of definitive management is a time of anxiety for the patient and, if prolonged, presents the opportunity for disease progression. For these reasons, standards have been set which aim at minimizing delay [37]. Also of relevance in this regard is the recognition that colonoscopy is not merely a diagnostic procedure, but has therapeutic capacity [38], and it is essential that the endoscopist carrying out screening colonoscopy has the necessary expertise to remove all but the most demanding lesions.

\section{Colonoscopic surveillance following adenoma removal}

The primary aims of colonoscopic surveillance are to reduce the morbidity and mortality from CRC by removing high-risk adenomas before they have had a chance to become malignant and by detecting invasive cancers at an early, curable stage. However, colonoscopy is a costly, invasive and scarce resource and should be undertaken only in people at increased risk, and at the lowest frequency deemed adequate to provide protection against the development of cancer. If colonoscopy surveillance is undertaken, it should be performed to the highest standard.

Chapter 9 includes 24 graded recommendations dealing with surveillance after removal of adenomas and a comprehensive strategy suitable for surveillance of patients attending screening programmes anywhere in the EU [23]. The recommendations reflect the fact that patients with previous adenomas are at increased risk for recurrent adenomas and hence CRC. The risk is thought to be linked to the number, size and histological grade of adenomas found and removed during baseline colonoscopy.

On this basis, patients can be divided into low-, intermediateand high-risk groups, and the interval to the first follow-up examination can vary accordingly. A reassessment can be made based on findings at the first and subsequent follow-up examinations. The risk stratification is predicated on an assumption that the initial and subsequent colonoscopies are of high quality and that there is complete removal of any detected lesions. The indication and interval for surveillance is determined primarily by the presumed risk for recurrence of advanced adenomas and cancer, but also by age, co-morbidity and patient wishes.

Because surveillance colonoscopy consumes considerable resources, countries that have difficulty meeting the demand might not be able to sustain reasonable waiting times. Screening programmes should therefore have a policy on surveillance with a hierarchy of action for different risk groups based on resource availability. The policy may limit surveillance to the high-risk group if sufficient resources are not available to include people with lower risk. 


\section{Communication}

Chapter 10 provides 35 recommendations dealing with communication [24]. CRC screening programmes can only be successful if they ensure that as many people as possible in the target population receive the relevant information to enable them to make an informed decision about attending screening. People using CRC screening services should receive accurate and accessible information, based on the most recent available evidence about the test proposed and its potential contribution to reduce illness, as well as information about potential risks, side-effects and limitations. Achieving this goal is challenging, because of the complexity of CRC screening programmes compared with other established programmes such as breast cancer or cervical cancer screening. This complexity may be an additional cause of anxiety for participants and therefore needs to be addressed in the communication strategy. People invited to screening therefore also need specific and clear instructions on how to use the FOBT kit or perform the bowel cleansing procedure.

The recommendations include information strategies, tools and interventions that can be used in current or future CRC screening programmes. They provide guidance specifically for screening programmes based on the FOBT, which is also the most frequently used test in programmes implemented in the EU. However, most of the recommendations can also be applied to programmes based on other tests.

\section{Performance standards}

Numerous measures, indicators and standards of performance are provided in the chapters dealing with evaluation and interpretation of screening outcomes [17], and quality assurance of endoscopy [19] and pathology [21] in CRC screening and diagnosis. The extensive consensus documented in the guidelines on relevant definitions and standards was facilitated by discussions in the International Colorectal Cancer Screening Network that demonstrated the need for further progress in programme monitoring and evaluation [39]. The executive summary includes a table of the performance standards [26]. All targets should be constantly reviewed in the light of experience and revised accordingly with regard to results achieved and best clinical practice. As far as possible, the targets given refer to men and women aged 50 74 years invited to and/or attending a CRC screening programme.

\section{Discussion}

$\nabla$

Quality assurance aims to ensure that an endeavour leads to the outcome for which it is intended. This principle also applies to complex systems, such as screening programmes designed to lower the burden of colorectal cancer (CRC) in the population. Over 100 million men and women in the European Union (EU) are in the age range currently recommended by the Council of the EU for CRC screening (50-74 years). By 2007, CRC screening programmes were running or being established in 12 EU countries $[13,40]$. Since then, screening programmes have been expanded or initiated in several EU countries. At any given time, only a relatively small proportion of those attending screening will have latent disease and can therefore directly benefit from early detection and treatment, However, all participants are exposed to the risks of screening such as anxiety and morbidity due to false-positive screening results, and the risk of invasive procedures for detection and/or removal of suspicious colorectal tissue. Although the risks may be slight, they add up in the large number of people exposed to screening. Effective quality assurance ensures that the balance between the collective risk and the achieved benefit remains acceptable.

Experience gained from piloting and implementing numerous cancer screening programmes in the EU confirms the wellknown observation that overall screening outcome depends on the level of performance at each step in the process of screening [3,13-16,41-43]; see also [44]. To maximize the benefit and minimize the risk of CRC screening, quality must be optimal throughout the process, and that includes the identification and personal invitation of the target population, the performance of the screening test and, if necessary, the diagnostic work-up of screen-detected lesions, and treatment, surveillance and aftercare $[2,3]$.

Implementation of organized screening programmes, as opposed to 'opportunistic' case-finding is recommended because they include an administrative structure responsible for service delivery, quality assurance and evaluation. Population-based programmes generally require a high degree of organization in order to identify and personally invite each person in the eligible target population. Personal invitation aims to give each eligible person an equal chance of benefiting from screening and thereby reduce health inequalities. As with evidence-based screening for breast or cervical cancer, the population-based approach to programme implementation is also recommended for CRC screening because it provides an organizational framework conducive to effective management and continuous improvement of the screening process, such as through linkage with population and cancer registries for optimization of invitation to screening and for evaluation of screening performance and impact [3,13-17]. Nationwide implementation of population-based screening programmes makes services performing to high standards available to the entire population eligible to attend screening. Large numbers of professionals undertake further specialization in order to meet the screening standards. Consequently, these nationwide efforts also contribute to widespread improvement in diagnosis and management of symptomatic disease $[2,3,13]$.

A number of internationally recognized guidelines and recommendations for best practice in CRC screening have been published elsewhere in recent years [45-52]. Numerous screening programmes, or scientific societies in their respective countries, have developed or recommended evidence-based guidelines and standards dealing with key elements of the screening process; see for example [53-57]. The EU guidelines are unique, however, because of their broad scope and detail and because they do not focus on indicating which methods can be recommended for screening. Although faecal occult blood testing for men and women in the age range 50-74 years is the only CRC screening method currently recommended by the EU [11], the European guidelines do not indicate a preference for this or any other method for use in CRC screening. Instead they provide comprehensive guiding principles and detailed, evidence-based recommendations on quality assurance that should be followed when implementing the screening methods currently employed in publicly mandated programmes in EU countries (FOBT, flexible sigmoidoscopy and colonoscopy).

The new EU guidelines are the first internationally developed, evidence-based, comprehensive guidelines dealing with the entire process of CRC screening. While all of the innovative elements in the new EU screening guidelines cannot be mentioned here, a few examples show how recent developments have been taken into account. 
Differing levels of endoscopist competence have implications for planning the location of endoscopy services for a CRC screening programme, and this is one of the many new elements in the chapter dealing with quality assurance in endoscopy; see Chapter 5 [19].

The inclusion of recommendations dealing with non-polypoid colorectal lesions and serrated lesions, some of which are difficult to detect due to their non-polypoid morphology, is another innovative aspect of the guidelines; see Chapter 7 [21] and the annex to Chapter 7 [25]. Although the existence of these lesions had been reported earlier, their appreciable prevalence and potential significance in diagnosis and management of CRC attracted attention in the western literature during the development of the EU guidelines $[58,59]$. Sessile serrated lesions are often found in the proximal colon [25]. In a non-population-based screening setting in North America, interval cancers have been associated with proximal location and molecular traits, such as CpG island methylation phenotype (CIMP) [60], that occur in most sessile serrated lesions and traditional serrated adenomas [25]. Under-detection of non-polypoid and serrated lesions may therefore play a role in study results that have not shown a protective effect of colonoscopy against CRC mortality in the right colon $[61,62]$. The international discussions on the significance of these lesions, during the development of the guidelines, stimulated further efforts to clarify appropriate methods of histologic reporting and clinical management [59] and led to related recommendations in the guidelines $[21,25]$. Since then, recent findings at two academic endoscopy units in North America have indicated that the prevalence of proximal colon serrated lesions in patients undergoing screening colonoscopy in a clinical setting may be higher than previously reported [63] and a significant proportion of proximal serrated lesions may be missed during colonoscopy [64]. Interval cancers have also been associated with proximal location in a population-based screening setting in Europe [65]. These findings also illustrate the importance of the recommendations in the guidelines for routine documentation of the morphology and topography of lesions detected in CRC screening [19,21].

The European guidelines also include the first comprehensive classification for the histology of lesions detected in CRC screening; that is applicable worldwide; see Chapter 7, Table 7.1 [21]. A selection of images and digital slides showing the histopathology of lesions commonly detected in screening programmes, as well as some images illustrating pitfalls in histopathological interpretation, has also been established [66]. This depository for instructive images will facilitate the exchange of experience between programmes and professionals within and beyond the borders of the EU.

Another example of the innovative character of the new EU guidelines is the first European protocol for surveillance of people found to be at elevated risk for development of CRC because of detection of adenomas at screening; see Chapter 9 [23]. Guidance on surveillance was deemed to be important by the editors and authors because surveillance on an inappropriate scale has the potential to expose patients to unnecessary risks and to prohibit implementation of nationwide CRC screening programmes because of unnecessary consumption of limited colonoscopy resources; see also $[45,67]$.

The detailed recommendations on communication, particularly on the essential elements to be included in invitation letters and information brochures for CRC screening, are an additional resource in the guidelines that can help to lower barriers to partici- pation and thereby help to make high quality screening available to all EU citizens; see Chapter 10 [24].

The comprehensive recommendations in the European guidelines are based on an extensive body of evidence; nevertheless, any aspect in the process of CRC screening could be improved through additional research and further exchange of experience between countries, programmes and other stakeholders. The authors, editors, contributors and reviewers who have participated in the development of the first edition of the guidelines therefore recommend that these efforts continue and that the evidence base and content of the guidelines is continuously updated. But keeping recommendations up to date is no guarantee that they will be followed or that effective CRC screening programmes will be implemented where they are needed. A number of criteria for successful implementation of cancer screening programmes have been identified in the chapter on organization [16]. This is an important area in which knowledge is expanding [68-71] and should be further developed to make effective use of CRC screening as a tool of cancer control.

\section{Conclusions}

$\nabla$

In a state-of-the-art process, wide consensus has been achieved on a comprehensive package of evidence-based recommendations for quality assurance in CRC screening in the EU. Given the universally applicable guiding principles on which the guidelines are based and the broad spectrum of cultural and economic health care settings in the EU, the recommendations are relevant to any country or region with a burden of disease appropriate for screening in the coming years. Application of the recommendations and standards in these guidelines will facilitate quality management and promote the international exchange of information and experience between programmes that is essential for continuous quality improvement. Over time this will help to prevent deaths due to CRC and will improve the quality of life of many of the millions of people potentially affected by one of the most common cancers in Europe and the world.

It would be short-sighted, however, to assume that all of the problems of quality assurance in CRC screening and diagnosis have been solved. Coordinated additional resources are required for continuous updating of the evidence-based recommendations and standards, including resources for additional research and collaboration between countries, regions and programmes in implementation of the guidelines. Resources are also needed for capacity building in screening, diagnosis and therapy of CRC, to reduce waiting times. Appropriate political commitment and investment at an early stage is likely to save considerable resources later on, when the full impact of these improvements will become discernible.

\section{Acknowledgments}

$\nabla$

The activities described in this publication were co-funded by the European Union through the EU Public Health Programme (grant agreement no.2005317: Development of European Guidelines for Quality Assurance of Colorectal Cancer Screening). Co-funding in the framework of the grant agreement was also provided by the following partner institutions: Oxford University Cancer Screening Research Unit, Cancer Epidemiology Unit, University of Oxford, Oxford, United Kingdom; Unit of Cancer Epidemiology, 
Centre for Cancer Epidemiology and Prevention, CPO Piemonte, AO Città della Salute e della Scienza di Torino, Turin, Italy; Public Association for Healthy People, Budapest, Hungary; European Cancer Patient Coalition (ECPC), Utrecht, Netherlands; Quality Assurance and Screening Groups, Section of Early Detection and Prevention, International Agency for Research on Cancer, Lyon, France. Additional financial support was received from the Public Affairs Committee of the United European Gastroenterology Federation, and from a cooperative agreement between the American Cancer Society and the Division of Cancer Prevention and Control at the Centers for Disease Control and Prevention, Atlanta, Georgia, United States of America.

\section{Disclaimer}

\section{$\nabla$}

The views expressed in this document are those of the authors and do not necessarily represent the official position of the European Commission or the Centers for Disease Control and Prevention. Neither the European Commission nor any other organisation, or person can be held responsible for any use that may be made of the information in this document.

Competing interests: Dr. Wendy Atkin has received significant non-monetary research support from Eiken Chemicals for reagents and machine lease for processing immunochemical faecal occult blood tests. The support is ongoing and will total less than $£ 80$ 000.Dr Hermann Brenner is employed by The German Cancer Research Center (DKFZ) that has received significant research support from Eiken Chemicals (less than $40000 €$ ) for previously and currently running studies on colorectal cancer detection. The following companies have provided the DKFZ with faecal occult blood tests free of charge for previously and currently running evaluation studies: ulti med, Ahrensburg, Germany; DIMA, Gottingen, Germany; Beckman Coulter, Krefeld, Germany; CAREdiagnostica, Voerde, Germany; Preventis, Bensheim, Germany; Quidel, San Diego, California. The total value of the non-monetary support is less than 100 000€. The German Cancer Research Center (DKFZ) has received significant research support from Epigenomics (less than 125 000€).Dr Michael Bretthauer's research unit at the Oslo University Hospital has received research grants and non-monetary research support of less than $25000 €$ from the companies Olympus and Falk.Dr David Liebermann has served on the advisory board of Exact Sciences. He received less than $3000 €$ for this activity to date.Dr Christian Pox has received lecture honoraria and travel support of less than $9000 €$ from the following manufacturers of pharmaceuticals, diagnostics, medical equipment and other health products: Dr Falk Pharma, Hitachi and Roche. He has also received consultancy fees of $1500 €$ for attending an Advisory Board Meeting of the Abbot company, a broad-based health care manufacturer, and $2100 €$ from the AQUA Institute, Germany, a private entity dedicated to quality assurance research and implementation that is mandated by the Federal Committee of the German Statutory Health Insurance System to implement a nationwide quality assurance scheme.Dr Wolff Schmiegel is the holder of one patent and the co-holder of three patents covering technologies related to screening and diagnosis of colorectal tumours. He is also co-holder of a patent covering substances potentially suitable for prevention and treatment of colorectal polyps. He has received consultancy fees of less than $2000 €$ from Astra Zeneca and consultancy fees, lecture honoraria and travel support totalling less than $16000 €$ from
Roche. He has also received lecture honoraria from Abbott, Pfizer and Falk. The Medical Faculty of the Ruhr University in Germany where he works has received institutional research funding of less than $160000 €$ from Roche and the pharmaceutical manufacturer Sanofi Aventis for studies in colorectal cancer screening and diagnosis.Dr Schmiegel is the sole shareholder (25 000€) of Medmotive $\mathrm{GmbH}$, a holding that until 2010 controlled 25\% of the company Westdeutsches Darm-Centrum GmbH with a capital investment of $25000 €$. The aim of these companies is to develop and coordinate a quality-assured network in colorectal oncology through such activities as consulting, development of therapeutic standards, specialized training and lobbying key stakeholders.Dr Schmiegel has received consultancy fees of less than $15000 €$ from Amgen, Apceth, Astra Zeneca, Merck and Roche.Dr Nereo Segnan has received consultancy fees of less than $1500 €$ from Roche Diagnostics Ltd for his participation at an Advisory Board Meeting on CRC screening.Dr Graeme Young has received consultancy fees (less than 10 000€) from Quidel Corporation, a manufacturer of diagnostic products. Eiken Chemicals has provided Flinders University where he works with faecal occult blood tests free of charge for studies (total value less than $10000 €$ ).

\section{Institutions}

${ }^{1}$ International Agency for Research on Cancer, Lyon, France

${ }^{2}$ NHS Cancer Screening Programmes Sheffield, United Kingdom

${ }^{3}$ Oxford University Cancer Screening Research Unit, Cancer Epidemiology Unit, University of Oxford, Oxford, United Kingdom

${ }^{4}$ CPO Piemonte, AO Città della Salute e della Scienza di Torino, Turin Italy ${ }^{5}$ Imperial College London, London, United Kingdom

${ }^{6}$ Bowel Cancer Screening Southern Programme Hub, Royal Surrey County Hospital NHS Foundation Trust, Guildford, United Kingdom

${ }^{7}$ University of Surrey, Guildford, United Kingdom

${ }^{8}$ Erasmus MC, Rotterdam, the Netherlands

${ }^{9}$ Finnish Cancer Registry, Helsinki, Finland

10 The Institute of Cancer Research, Royal Cancer Hospital, Sutton, United Kingdom

${ }^{11}$ Leeds Institute of Molecular Medicine, St James' University Hospital, Leeds, United Kingdom

${ }^{12}$ Ninewells Hospital and Medical School, Dundee, United Kingdom

${ }^{13}$ Institute of Pathology, Klinikum Bayreuth, Bayreuth, Germany

${ }^{14}$ Department of Medical Gastroenterology, Stavanger University Hospital, Stavanger, Norway

${ }^{15}$ Central Research Institute of Ambulatory Health Care, Berlin, Germany

${ }^{16}$ Direction Générale de la Santé, Paris, France

${ }^{17}$ Croatian National Institute of Public Health, Zagreb, Croatia

${ }^{18}$ University of Zagreb School of Medicine, Zagreb, Croatia

${ }^{19}$ CONICET/CEDES, Buenos Aires, Argentina

20 University of Oxford, Oxford, United Kingdom

${ }^{21}$ Mario Negri Institute for Pharmacological Research, Milan, Italy

22 Karolinska Institutet, Stockholm, Sweden

${ }^{23}$ German Cancer Research Center, Heidelberg, Germany

24 Institute of Health and Society, University of Oslo, Oslo, Norway

${ }^{25}$ National Cancer Registry, Cork, Ireland

${ }^{26}$ Formerly International Agency for Research on Cancer, Lyon, France

${ }^{27}$ A. Gemelli University Hospital, Rome, Italy

28 Wolfson Institute of Preventive Medicine, Queen Mary University of London, United Kingdom

${ }^{29}$ Cancer Institute \& Hospital, Chinese Academy of Medical Sciences, Beijing, China

${ }^{30}$ American Cancer Society, Atlanta, Georgia, United States of America

${ }^{31}$ Academic Medical Centre, Amsterdam, the Netherlands

32 National Health Screening Services, Ministry of Health, Elderly \& Community Care, Valletta, Malta

33 University of Applied Sciences FH Joanneum, Graz, Austria

${ }^{34}$ Catalan Cancer Strategy, L'Hospitalet de Llobregat, Spain

${ }^{35}$ Digestive Cancer Registry of Burgundy, INSERM U866, University and CHU, Dijon, France

${ }^{36}$ Lynn's Bowel Cancer Campaign, Twickenham, United Kingdom

37 National Israeli Breast and Colorectal Cancer Detection, Haifa, Israel

38 Department of Gynecological Pathology and Cytology, University Medical Center Ljubljana, Slovenia

${ }^{39}$ University of Vermont, Burlington, Vermont, United States of America

${ }^{40}$ Cancer Prevention and Research Institute (ISPO), Florence, Italy

${ }^{41}$ National Cancer Centre, Tokyo, Japan

${ }^{42}$ Cancer League of Eastern Switzerland, St. Gallen, Switzerland 
${ }^{43}$ Cancer Registry of Norway, Oslo, Norway

44 Telemark Hospital, Skien, Norway

${ }^{45}$ Danish Cancer Society, Copenhagen, Denmark

${ }^{46}$ Hospital General Universitario de Alicante, Alicante, Spain

${ }^{47}$ Maria Sklodowska-Curie Memorial Cancer Centre and Medical Centre for Postgraduate Education, Warsaw, Poland

48 Lithuanian Cancer Registry, Vilnius, Lithuania

49 U1086 INSERM - UCBN, CHU Caen, France

50 The Catholic University of Korea College of Medicine, Seoul, Republic of Korea

51 St. George's Hospital, London, United Kingdom

52 University of Latvia, Riga, Latvia

${ }^{53}$ Oregon Health \& Science University, Portland, Oregon, United States of America

54 University of Copenhagen, Copenhagen, Denmark

55 MaMMa Healthcare Institute, Budapest, Hungary

${ }^{56}$ Health Administration Central Region Portugal, Aveiro, Portugal

57 National Public Health Institute, Ljubljana, Slovenia

${ }^{58}$ Gastroenterology Unit, Valduce Hospital, Como, Italy

${ }^{59}$ GlaxoSmithKline Pharma Europe, London, United Kingdom

${ }^{60}$ Regional Health Administration, Coimbra, Portugal

${ }^{61}$ Centers for Disease Control and Prevention, Atlanta, Georgia, United States of America

62 Prof. Dr lon Chiricuță, Cluj-Napoca, Romania

${ }^{63}$ Catalan Institute of Oncology, L'Hospitalet de Llobregat, Spain

64 University of North Carolina, Chapel Hill, North Carolina, United States of America

${ }^{65}$ Ruhr Universität, Bochum, Germany

${ }^{66}$ Epidemiology and Cancer Registry, Institute of Oncology Ljubljana, Slovenia

${ }^{67}$ University of Toronto and Cancer Care Ontario, Toronto, Canada

68 Bispebjerg University Hospital, Copenhagen, Denmark

${ }^{69}$ Institut Arnault Tzanck, St Laurent du Var, France

${ }^{70}$ Mount Sinai Hospital, Toronto, Canada

71 Institute for Cancer Research and Treatment, Candiolo-Torino, Italy

${ }^{2}$ Faculdade de Medicina - Universidade de Coimbra, Coimbra, Portugal

73 Ministry of Health, Luxembourg, Luxembourg

${ }^{74}$ Cancer Foundation of India, Kolkata, India

75 The University of Chicago, Department of Medicine, Hematology-Oncology Section, Center for Clinical Cancer Genetics, Global Health, Chicago, United States of America

${ }^{76}$ University Hospitals Coventry \& Warwickshire NHS Trust, Coventry, United Kingdom

${ }_{77}$ Charles University and Military University Hospital, Prague, Czech Republic

${ }^{78}$ Chinese Academy of Medical Sciences, Beijing, China

${ }^{79}$ Department of Cancer Screening, Stockholm Gotland Regional Cancer Centre, Stockholm, Sweden

${ }^{80}$ University of Leuven, Leuven, Belgium

${ }^{81}$ Agenzia Sanitaria e Sociale Regionale-Regione Emilia-Romagna, Bologna, Italy

82 University of Miami, Miami, Florida, United States of America

${ }^{83}$ Niigata University, Niigata, Japan

${ }^{84}$ Memorial Sloan-Kettering Cancer Center, New York, United States of America

${ }^{85}$ Gastrointestinal Services, Flinders University, Adelaide, Australia

86 State Patient Fund, Vilnius, Lithuania

${ }^{87}$ NHS Endoscopy, Leicester, United Kingdom

\section{References}

1 Ferlay J, Shin HR, Bray F et al. GLOBOCAN 2008, Cancer Incidence and Mortality Worldwide: IARC CancerBase No. 10 [Internet]. Lyon, France: International Agency for Research on Cancer; 2010: Available at: http://globocan.iarc.fr Accessed: Sept 92012

2 von Karsa L, Lignini TA, Patnick J et al. The dimensions of the CRC problem. Best Pract Res Clin Gastroenterol 2010; 24: 381 - 396

3 Lansdorp-Vogelaar I, von Karsa L. European guidelines for quality assurance in colorectal cancer screening and diagnosis. First edition - Introduction. Endoscopy 2012; 44 : SE15-SE30

4 Atkin WS, Edwards R, Kralj-Hans I et al. Once-only flexible sigmoidoscopy screening in prevention of colorectal cancer: a multicentre randomised controlled trial. Lancet 2010; 375: 1624-1633

5 Mandel JS, Church TR, Bond JH et al. The effect of fecal occult-blood screening on the incidence of colorectal cancer. N Engl J Med 2000; 343: $1603-1607$

6 Segnan N, Armaroli P, Bonelli L et al. Once-only sigmoidoscopy in colorectal cancer screening: follow-up findings of the Italian Randomized Controlled Trial - SCORE. J Natl Cancer Inst 2011; 103: 1310-1322
7 Schoen RE, Pinsky PF, Weissfeld JL et al. Colorectal-cancer incidence and mortality with screening flexible sigmoidoscopy. N Engl J Med 2012; 366: $2345-2357$

8 Hardcastle JD, Chamberlain JO, Robinson $\mathrm{MH}$ et al. Randomised controlled trial of faecal-occult-blood screening for colorectal cancer. Lancet $1996 ; 348$ : $1472-1477$

9 Kronborg 0 , Fenger $C$, Olsen J et al. Randomised study of screening for colorectal cancer with faecal-occult-blood test. Lancet 1996; 348: $1467-1471$

10 Mandel JS, Church TR, Ederer F et al. Colorectal cancer mortality: effectiveness of biennial screening for fecal occult blood. J Natl Cancer Inst 1999; 91: $434-437$

11 Council of the European Union. Council Recommendation of 2 December 2003 on cancer screening (2003/878/EC). Off J Eur Union 2003: $34-38$

12 Wilson JMG, Jungner G. Principles and practice of screening for disease. Geneva, Switzerland: WHO; 1968: Available at: http://whqlibdoc. who.int/php/WHO_PHP_34.pdf Accessed: October 92012

13 von Karsa L, Anttila A, Ronco $G$ et al. Cancer screening in the European Union. Report on the implementation of the Council Recommendation on cancer screening - First report. Luxembourg: European Commission; 2008: Available at: http://ec.europa.eu/health/archive/ph_determinants/genetics/documents/cancer_screening.pdf Accessed: February 112012

14 Arbyn M, Anttila A, Jordan J et al., eds. European guidelines for quality assurance in cervical cancer screening. Second edition. Luxembourg: European Commission, Office for Official Publications of the European Communities; 2008

15 Perry $N$, Broeders $M$, de Wolf $C$ et al., eds. European guidelines for quality assurance in breast cancer screening and diagnosis. Fourth edition. Luxembourg: European Commission, Office for Official Publications of the European Communities; 2006

16 Malila $N$, Senore C, Armaroli P. European guidelines for quality assurance in colorectal cancer screening and diagnosis. First edition - Organisation. Endoscopy 2012; 44 : SE31 - SE48

17 Moss $S$, Ancelle-Park $R$, Brenner $H$. European guidelines for quality assurance in colorectal cancer screening and diagnosis. First edition Evaluation and interpretation of screening outcomes. Endoscopy 2012; 44 : SE49 - SE64

18 Halloran SP, Launoy G, Zappa M. European guidelines for quality assurance in colorectal cancer screening and diagnosis. First edition - Faecal occult blood testing. Endoscopy 2012; 44: SE65 - SE87

19 Valori R, Rey JF, Atkin WS et al. European guidelines for quality assurance in colorectal cancer screening and diagnosis. First edition - Quality assurance in endoscopy in colorectal cancer screening and diagnosis. Endoscopy 2012; 44: SE88-SE105

20 Steele RJ, Rey JF, Lambert R. European guidelines for quality assurance in colorectal cancer screening and diagnosis. First edition - Professional requirements and training. Endoscopy 2012; 44: SE106-SE115

21 Quirke P, Risio M, Lambert R et al. European guidelines for quality assurance in colorectal cancer screening and diagnosis. First edition - Quality assurance in pathology in colorectal cancer screening and diagnosis. Endoscopy 2012; 44: SE116-SE130

22 Steele RJ, Pox C, Kuipers EJ et al. European guidelines for quality assurance in colorectal cancer screening and diagnosis. First edition - Management of lesions detected in colorectal cancer screening. Endoscopy 2012; 44: SE140 - SE150

23 Atkin WS, Valori R, Kuipers EJ et al. European guidelines for quality assurance in colorectal cancer screening and diagnosis. First edition Colonoscopic surveillance following adenoma removal. Endoscopy 2012; 44: SE151 - SE163

24 Austoker J, Giordano L, Hewitson P et al. European guidelines for quality assurance in colorectal cancer screening and diagnosis. First edition Communication. Endoscopy 2012; 44: SE164-SE185

25 Vieth M, Quirke P, Lambert R et al. European guidelines for quality assurance in colorectal cancer screening and diagnosis. First edition Annotations of colorectal lesions. Endoscopy 2012; 44: SE131 - SE139

26 von Karsa L, Patnick J, Segnan N. European guidelines for quality assurance in colorectal cancer screening and diagnosis. First edition - Executive summary. Endoscopy 2012; 44: SE1 - SE8

27 European guidelines for quality assurance in colorectal cancer screening and diagnosis - First edition.Segnan N, Patnick J, von Karsa L et al. , eds. Luxembourg: European Commission, Publications Office of the European Union; 2010 
28 Minozzi S, Armaroli P, Segnan N. European guidelines for quality assurance in colorectal cancer screening and diagnosis. First edition - Principles of evidence assessment and methods for reaching recommendations. Endoscopy 2012; 44: SE9-SE14

29 Minozzi S, Armaroli P, Segnan N. Principles of evidence assessment and methods for reaching recommendations. In: Segnan N, Patnick J, von Karsa L, eds European guidelines for quality assurance in colorectal cancer screening and diagnosis - First edition. Luxembourg: European Commission, Office for Official Publications of the European Union; 2010: IL-LIX

30 Moher D, Cook DJ, Eastwood S et al. Improving the quality of reports of meta-analyses of randomised controlled trials: the QUOROM statement. Quality of reporting of meta-analyses. Lancet 1999; 354 : $1896-1900$

31 Higgins JPT, Altman DG. Assessing risk of bias in included studies. In: Higgins JPT, Green S, eds. Cochrane handbook for systematic reviews of interventions. UK: Wiley-Blackwell; 2008

32 EPOC. Cochrane Effective Practice and Organisation of Care Group (EPOC). Data 2002: Available at: http://www.epoc.cochrane.org/en/ handsearchers.html Accessed October 92012

33 Wells GA, Shea B, O'Connell $D$ et al. The Newcastle-Ottawa Scale (NOS) for assessing the quality of nonrandomised studies in meta-analyses. 2010: Available at: http://www.ohri.ca/programs/clinical_epidemiology/oxford.htm Accessed October 92012

34 Whiting P, Rutjes AW, Reitsma JB et al. The development of QUADAS: a tool for the quality assessment of studies of diagnostic accuracy included in systematic reviews. BMC Med Res Methodol 2003; 3: 25

35 Shiffman RN, Shekelle P, Overhage JM et al. Standardized reporting of clinical practice guidelines: a proposal from the Conference on Guideline Standardization. Ann Intern Med 2003; 139: 493 - 498

36 SIGN. Scottish Intercollegiate Guidelines Network - Guidelines for the management of colorectal cancer. 2003: Available at: http://www. sign.ac.uk/pdf/sign67.pdf Accessed: February 112012

37 NHS. Bowel Screening Programme Clinical Standards. Scotland: NHS Quality Improvement; 2007: Available at: http://www.bowelscreening.scot.nhs.uk/wp-content/uploads/2007/06/bowelsc_stnf_feb07.pdf Accessed: February 112012

38 Cotton $P B$, Williams $C B$. Colonoscopic polypectomy and therapeutic procedures. In: Cotton $\mathrm{PB}$, Williams $\mathrm{CB}$, eds. Practical gastrointestinal endoscopy. 4th edn. Oxford: Blackwell Science; 1996: 275-302

39 Benson VS, Atkin WS, Green J et al. Toward standardizing and reporting colorectal cancer screening indicators on an international level: The International Colorectal Cancer Screening Network. Int J Cancer 2012; 130: 2961 - 2973

40 Zavoral M, Suchanek S, Zavada F et al. Colorectal cancer screening in Europe. World J Gastroenterol 2009; 15: 5907 -5915

41 Arbyn M, Anttila A, Jordan J et al. European guidelines for quality assurance in cervical cancer screening. Second edition - Summary document. Ann Oncol 2010; 21: 448-458

42 Perry $N$, Broeders $M$, de Wolf $C$ et al. European guidelines for quality assurance in breast cancer screening and diagnosis. Fourth edition Summary document. Ann Oncol 2008; 19: 614-622

43 von Karsa L. Mammographie Screening - umfassendes, populationsbezogenes Qualitätsmanagement ist hier gefragt! [Mammography screening - comprehensive, population-based quality assurance is required!]. Z Allg Med 1995; 71: $1863-1867$

44 Donabedian $A$. The quality of care. How can it be assessed? JAMA 1988; 260: $1743-1748$

45 Winawer S, Classen M, Lambert R et al. World Gastroenterology Organisation/International Digestive Cancer Alliance guidelines: Colorectal cancer screening. Available at: 2007: http://www.worldgastroenterololgy.org/assets/downloads/en/pdf/guidelines/06_colorectal_cancer_screening.pdf Accessed: August 312012

46 Lee BI, Hong SP, Kim SE et al. Korean guidelines for colorectal cancer screening and polyp detection. Clin Endosc 2012; 45: 25 - 43

47 Brink D, Barlow J, Bush K et al. Colorectal cancer screening. Available at: 2012: http://bit.ly/Colorectal0512 Accessed: August 242012

48 Rex DK, Johnson DA, Anderson JC et al. American College of Gastroenterology guidelines for colorectal cancer screening 2009 [corrected]. Am J Gastroenterol 2009; 104: 739 - 750

49 Levin B, Lieberman DA, McFarland B et al. Screening and surveillance for the early detection of colorectal cancer and adenomatous polyps, 2008: a joint guideline from the American Cancer Society, the US Mul-
ti-Society Task Force on Colorectal Cancer, and the American College of Radiology. Gastroenterology 2008; 134: 1570 -1595

50 Lieberman D, Nadel M, Smith RA et al. Standardized colonoscopy reporting and data system: report of the Quality Assurance Task Group of the National Colorectal Cancer Roundtable. Gastrointest Endosc 2007; 65: $757-766$

51 Sung JJ, Lau JY, Young GP et al. Asia Pacific consensus recommendations for colorectal cancer screening. Gut 2008; 57: 1166-1176

52 U.S. Preventive Services Task Force. Screening for colorectal cancer: U.S. Preventive Services Task Force recommendation statement Ann Intern Med 2008; 149: 627-637

53 Rabeneck L, Rumble RB, Axler J et al. Cancer Care Ontario colonoscopy standards: standards and evidentiary base. Can J Gastroenterol 2007; $21: 5 \mathrm{D}-24 \mathrm{D}$

54 Jover $R$, Herraiz $M$, Alarcon $O$ et al. Clinical practice guidelines: quality of colonoscopy in colorectal cancer screening. Endoscopy 2012; 44: $444-451$

55 Schmiegel W, Pox C, Reinacher-Schick A et al. S3-Leitlinie "Kolorektales Karzinom" Ergebnisse evidenzbasierter Konsensuskonferenzen am 6 7. Februar 2004 und am 8./9. Juni 2007 (für die Themenkomplexe IV VI und VII) S3-Guideline "Colorectal Cancer" 2004/2008. Z Gastroenterol 2008; 46: 1 - 73

56 Cancer Care Ontario. Colorectal cancer screening. Surveillance guidelines. Available at: 2012: https://www.cancercare.on.ca/pcs/screening/coloscreening/cccstandardsguidelines/ Accessed: September 9 2012

57 Rabeneck L, Zwaal C, Goodman JH et al. Cancer Care Ontario guaiac fecal occult blood test (FOBT) laboratory standards: evidentiary base and recommendations. Clin Biochem 2008; 41: 1289-1305

58 Soetikno RM, Kaltenbach T, Rouse RV et al. Prevalence of nonpolypoid (flat and depressed) colorectal neoplasms in asymptomatic and symptomatic adults. JAMA 2008; 299: 1027-1035

59 Kudo S, Lambert R, Allen JI et al. Nonpolypoid neoplastic lesions of the colorectal mucosa. Gastrointest Endosc 2008; 68: 3-47

60 Arain MA, Sawhney M, Sheikh S et al. CIMP status of interval colon cancers: another piece to the puzzle. Am J Gastroenterol 2010; 105 1189- 1195

61 Baxter NN, Goldwasser MA, Paszat LF et al. Association of colonoscopy and death from colorectal cancer. Ann Intern Med 2009; 150: 1 -8

62 Brenner $H$, Hoffmeister $M$, Arndt V et al. Protection from right- and leftsided colorectal neoplasms after colonoscopy: population-based study. J Natl Cancer Inst 2010; 102: 89-95

63 Kahi CJ, Hewett DG, Norton DL et al. Prevalence and variable detection of proximal colon serrated polyps during screening colonoscopy. Clin Gastroenterol Hepatol 2011; 9: $42-46$

64 Kahi CJ, Li X, Eckert GJ et al. High colonoscopic prevalence of proximal colon serrated polyps in average-risk men and women. Gastrointest Endosc 2012; 75: $515-520$

65 Steele RJ, McClements $P$, Watling $C$ et al. Interval cancers in a FOBTbased colorectal cancer population screening programme: implications for stage, gender and tumour site. Gut 2012; 61: 576-581

66 Department of Pathology and Tumour Biology, Leeds Institute of Molecular Medicine, University of Leeds. European Union Bowel Cancer Screening Pathology Examples. Available at: http://www.virtualpathology.leeds.ac.uk/eu/examples.php Accessed: 17 November 2012

67 Winawer SJ, Zauber AG, Fletcher RH et al. Guidelines for colonoscopy surveillance after polypectomy: a consensus update by the US MultiSociety Task Force on Colorectal Cancer and the American Cancer Society. Gastroenterology 2006; 130: 1872-1885

68 Hill D, Dixon H. Prevention and Screening. Achieving behavioural changes in individuals and populations. In: Elwood JM, Sutcliffe SB eds Cancer Control. Oxford: Oxford University Press; 2010

69 Hanleybrown F, Kania J, Kramer M. Channeling change: making collective impact work. Stanford Social Innovation Review 2012: Available at: http://www.ssireview.org/blog/entry/channeling_change_making_collective_impact_work Accessed: October 102012

70 Lynge E, Tornberg S, von Karsa L et al. Determinants of successful implementation of population-based cancer screening programmes. Eur J Cancer 2012; $48: 743-748$

71 Martin-Moreno JM, Anttila A, von Karsa L et al. Cancer screening and health system resilience: keys to protecting and bolstering preventive services during a financial crisis. Eur J Cancer 2012; 48: 2212-2218 